


\title{
Oak Ridge National Laboratory Materials Highlights
}

\author{
James R. Wei-, Jr. \\ Metals and Ceramics Division \\ Rachel Daghir \\ Pennsylvania State University
}

December 1990

OAK RIDGE NATIONAL LABORATORY

Oak Ridge, Tennessee 37831 managed by

MARTIN MARIETTA ENERGY SYSTEMS, INC. for the U.S. DEPARTMENT OF ENERGY under contract DE-AC05-84OR21400 


\section{Oak Ridge National Laboratory Materials Highlights}

\section{Contents}

\section{Metals}

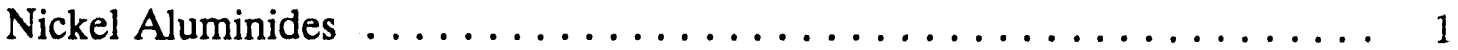

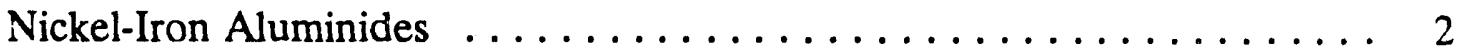

$\mathrm{Fe}_{3} \mathrm{Al}$-Based Iron Aluminides $\ldots \ldots \ldots \ldots \ldots \ldots \ldots$

Advanced Austenitic Alloys for Coal Utilization Applications . . . . . . . 6

Ceramics

Whisker-Reinforced Ceramic Composites ................ 7

Toughened Zircunia Ceramics ................... 8

Joining Ceramics ......................... 9

Fiber-Reinforced Ceramic-Matrix Composites . . . . . . . . . . . . . . 10

Fiber-Reinforced Composite Hot-Gas Filters . . . . . . . . . . . . . 12

Titanium Diboride . . . . . . . . . . . . . . . . . . . . . . . 13

Fabrication of High-Field Zinc Oxide Varistors by Sol-Gel Processing . . . . 14

Zirconia-Bonded Zirconia Fiber Insulation Structures . . . . . . . . . . 15

Materials Testing And Production

Pulsed Eddy-Current Nondestructive Testing . . . . . . . . . . . . 16

The Sigmajig: An Improved Hot-Cracking Test $\ldots \ldots \ldots \ldots \ldots \ldots \ldots$

Laser Diffraction Methods for High-Temperature Strain

Measurements .......................... 19

MHD Molten Metal Atomizer for Powder Production and

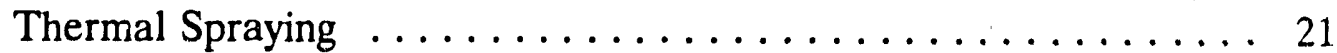

Microwave Sintering of Ceramics . . . . . . . . . . . . . . . . 22

The Thermomechanical Model Software Development Center:

A Technology Transfer Initiative ................. 24

Process for Impregnating a Concrete or Cement Body with a

Polymeric Material ..................... 26

For Further Information $\ldots \ldots \ldots \ldots \ldots \ldots \ldots \ldots \ldots \ldots$ 
Nickel Aluminides

J. R. Weir, Jr., and V. K. Sikka

(615) 574-4064 and (615) 574-5112

Metals and Ceramics Division

Oak Ridge National Laboratory

Oak Ridge, Tennessee 37831

The ductile-ordered $\mathrm{Ni}_{3} \mathrm{Al}$-based intermetallics developed at ORNL offer several unique advantages over high-temperature nickel-based and refractory metal alloys. These include: excellent oxidation resistance, lower density, increase in yield strength with increasing temperature up to $850^{\circ} \mathrm{C}$, an order of magnitude better fatigue life than nickel-based alloys, two orders of magnitude improvement in wear resistance with increase in temperature, and best cavitation erosion resistance among currently available materials. Because of those unique properties, nickel aluminides offer energy and economic advantages for many applications. The current program is helping to mature the technology for early applications.

To take advantage of nickel-aluminide intermetallics, this technology has been transferred to users and producers through licensing arrangements. Five companies are currently licensed which include Armco Research \& Technology, Cummins Engine Company, Hoskins Manufacturing Company, Metallamics Inc., and Valley Todeco. Additional suppliers are being added to the lisi ihrough sublicensing arrangements.

The application of nickel aluminides require additional work in the areas of composition optimization, casting and fabrication techniques, mechanical properties, weldability, and machinability. For the die applications, it has been demonstrated that an electroslag-remelting ingot gives the best mechanical properties. For the turbocharger application, the composition modifications were made to increase the room-temperature yield strength to $586 \mathrm{MPa}$ ( $85 \mathrm{ksi}$ ). Further composition modifications are currently under way to improve castability and fatigue properties. The welding process is near optimization for the use of nickel aluminides through the weld overlay process. The alloy has been sold commercially and has been confirmed for use as die material. Other applications are currently proprietary to the suppliers.

PATENT STATUS: $\quad$ U.S. Patents 4,731,221; 4,711,761; 4,612,165. 
Nickel-Iron Aluminides

\author{
C. T. Liu \\ (615) $574-4459$
}

Metals and Ceramics Division

Oak Ridge National Laboratory

Oak Ridge, Tennessee 37831

Nickel-iron aluminides are being developed to (1) strengther nickel aluminides by solid-solution hardening, (2) lower the material cost by reducing the nickel content, and (3) improve the hot ductility of nickel aluminides through the formation of a body-centered-cubic (B2) phase.

The most promising nickel-iron aluminide composition developed at the Oak Ridge National Laboratory is (all numbers in at. \%): $\mathrm{Ni}-18.0 \pm 1.0 \% \mathrm{Al}$ $12.0 \pm 1.0 \% \mathrm{Fe}-8.0 \pm 1.0 \% \mathrm{Cr}-0.2 \% \mathrm{Zr}-0.1 \% \mathrm{~B}$. Alloying with $10 \%$ iron (or above) increases the strength of $\mathrm{Ni}_{3} \mathrm{Al}$ below $800^{\circ} \mathrm{C}$. Chromium promotes the rapid formation of protective oxide scales and improves resistance to oxidation, corrosion, and environmental embrittlement. Both chromium and iron increase the stability of the bcc-ordered B2 phase. Zirconium improves the high-temperature properties of nickel aluminides but must be limited to less than $0.3 \%$; otherwise, it lowers the hot fabricability of the material. Boron is necessary to make the otherwise brittle intermetallic compound ductile at room temperature. Small amounts of titanium or molybdenum further improve corrosion resistance at elevated temperatures.

Corrosion studies have indicated that nickel-iron aluminides with $\geq 7 \%$ chromium are very resistant to sulfur attack. Sulfidation protection can also be provided by oxide films produced in air between $1000-1050^{\circ} \mathrm{C}$ in alloys with $\geq 3 \%$ chromium.

Nickel-iron aluminides have been successfully welded using both the electron beam and gas tungsien arc processes.

Current structural alloys, including austenitic stainless steels and nickel-based superalloys, generally do not have an adequate combination of strength, ductility, and corrosion resistance for structural use in advanced coal conversion systems. Coating materials such as FeCrAl are also idequate; although they possess good corrosion resistance, they lack adequate strength at high temperatures. However, nickel-aluminide-based materials are resistant to oxidation and increase in strength at high temperatures. 
PATENT STATUS:

1. Chromium-modified nickel-iron aluminide useful in sulfur-bearing environments: J. V. Cathcart and C. T. Liu, U.S. Patent 4,839,140.

2. Nickel aluminides and nickel-iron aluminides for use in oxidizing environments: C. T. Liu, U.S. Patent 4,731,221.

3. High-temperature fabricable nickel-iron aluminides: C. T. Liu, U.S. Patent $4,722,828$. 
$\mathrm{Fe}_{3} \mathrm{Al}$-Based Iron Aluminides

\author{
C. G. McKamey \\ (615) 574-6917 \\ Metals and Ceramics Division \\ Oak Ridge National Laboratory \\ Oak Ridge, Tennessee 37831
}

Although tests on iron aluminides are still under way, it appears that these alloys could prove to be an excellent low-cost alternative to stainless steels and nickel-based alloys.

The iron aluminides of current interest are a family of alloys based on the intermetallic compound $\mathrm{Fe}_{3} \mathrm{Al}$. Until recently, $\mathrm{Fe}_{3} \mathrm{Al}$ was too brittle to be of any practical use. However, it has been discovered at the Oak Ridge National Laboratory that small alloying additions can make these alloys workable. The room-temperature ductility has been improved from about $1 \%$ to about $15 \%$ by compositional modifications and control of microstructure. Tubes, sheets, and castings of iron aluminides have been successfully fabricated.

Because they are protected by the formation of an adherent $\mathrm{Al}_{2} \mathrm{O}_{3}$ fillm, iron aluminides are expected to be resistant to corrosion at high temperatures. They have already been shown to satisfactorily resist both high-temperature oxidation and damage in sulfur-bearing environments. Preliminary tests on the static aqueous corrosion of iron aluminides suggest that these alloys are also extremely resistant to corrosion in many moisture-bearing environments.

Iron aluminides are expected to cost much less than other corrosion-resistant alloys such as superalloys, nickel aluminides, and even stainless steels, because they rely on relatively inexpensive aluminum instead of expensive nickel and/or chromium to provide corrosion resistance. Alloying additions usually total less than $10 \%$ of the weight of the material.

The strength of $\mathrm{Fe}_{3} \mathrm{Al}$ is superior to the strengths of alloys such as type 316 stainless steel up to $600^{\circ} \mathrm{C}$. $\mathrm{Fe}_{3} \mathrm{Al}$ with alloying additions show increased creep and tensile strength at temperatures to $600^{\circ} \mathrm{C}$ without significant decrease in roorn-temperature ductility. Continued research is necessary to determine whether the high-temperature strength of these alloys above $600^{\circ} \mathrm{C}$ can be improved. 
Further studies on the properties of $\mathrm{Fe}_{3} \mathrm{Al}$-based iron aluminides are now under way, including impact, fracture toughness, and weldability studies, which until now have only been investigated in a preliminary manner.

PATENT STATUS: $\quad$ U.S. Patent $4,961,903$. 
Advanced Austenitic Alloys for Coal Utilization Applications

R. W. Swindeman

(615) 574-5108

Metals and Ceramics Division

Oak Ridge National Laboratory

Oak Ridge, Tennessee 37831

Screening tests (fabricability, mechanical properties, weldability, and oxidation behavior) were performed on three alloy groups. These alloys included lean austenitic stainless steels that were modifications of type 316 stainless steels, $20 \mathrm{Cr}-30 \mathrm{Ni}-\mathrm{Fe}$ alloys that were modifications of alloy $800 \mathrm{H}$, and nickel-chromium aluminides that were specifically designed for fossil energy applications. The results of these tests were compared to alloy design and performance criteria needed for austenitic alloys suitable as superheater/reheater tubing in advanced heat recovery systems.

The lean type 316 stainless steels were found to possess excellent strength and ductility if worked to an equivalent strain in the range 5-10\% prior to testing. They possessed marginal weldability, poor oxidation resistance, and adverse sensitivity to aging. Nonetheless, they proved to be superior to other stainless steels modified for strength and could be chromized for improved oxidation resistance. The most promising composition was produced as bare tubing by two commercial tubing fabricators and as clad tubing (alloys 690 and 671).

The modified $800 \mathrm{H}$ alloys also exhibited good strength and ductility in the worked condition. Their weldability was marginal, but their oxidation resistance was good. Again, the most promising composition was produced as tubing by two commercial tubing fabricators. Tubing was also clad with alloy 690 .

Research on the modified typed 316 stainless steel and modified alloy $800 \mathrm{H}$ has proceeded to corrosion, welding, and full-scale tubing tests.

PATENT STATUS: Patents have been issued for one group of lean stainless steels $(4,818,485)$ and for one group of modified alloy $800 \mathrm{H}$ compositions $(4,849,169)$. 


\title{
Whisker-Reinforced Ceramic Composites
}

\author{
T. N. Tiegs \\ (615) $574-5173$ \\ Metals and Ceramics Division \\ Oak Ridge National Laboratory \\ Oak Ridge, Tennessee 37831
}

Reinforcement with $\mathrm{SiC}$ whiskers has been shown to significantly improve the mechanical properties of alumina and mullite. For example, typical fine-grained alumina with ground surfaces has fracture toughness $\left(\mathrm{K}_{\mathrm{Ic}}\right)$ of 4.0 to $5.0 \mathrm{MPa} \cdot \mathrm{m}^{1 / 2}$ and flexural strength of $650 \mathrm{MPa}$ are obtained. These toughness and strength values are essentially maintained up to temperatures of at least $1000^{\circ} \mathrm{C}$. Crack bridging by the whiskers is the major toughening mechanism.

By increasing their fracture toughness, whisker-reinforced ceramics become less sensitive to flaw size. This results in improved resistance to slow crack growth for alumina-20 vol \% $\mathrm{SiC}$ whisker composites. The potential of $\mathrm{SiC}$ whisker-reinforced alumina is further enhanced when one notes that it displays excellent thermal shock resistance through temperature changes of up to $900^{\circ} \mathrm{C}$.

The final properties of the composites depend not only on the volume fraction of whiskers and the processing, but on the starting materials as well. Evaluation of whiskers from several commercial sources shows that alumina-SiC whisker incompatibility at elevated fabrication temperatures can result in severe degradation of the mechanical properties of the final composite. Processing of whisker-reinforced ceramic composites must therefore be tailored to specific powder-whisker combinations.

The improvement in the mechanical properties and wear resistance of the whisker-reinforced composites over monolithic ceramics is impressive. Recent results suggest that further improvements in mechanical properties can be attained by combining whisker reinforcement with transformation toughening through the addition of zirconia particles to the composite.

PATEN'I STATUS: $\quad$ U.S. Patents 4,652,413; 4,657,877; 4,916,092. Additional applications pending. 
Toughened Zirconia Ceramics

\author{
P. F. Becher \\ (615) 574-5157 \\ Metals and Ceramics Division \\ Oak Ridge National Laboratory \\ Oak Ridge, Tennessee 37831
}

The brittleness of ceramics currently restricts their use in structural components. If even a tiny crack forms it can grow very rapidly, leading to catastrophic failure of the ceramic component. Therefore, research efforts are exploring ways to increase the fracture toughness/resistance of ceramics in order to avoid fracture under service conditions.

Oak Ridge National Laboratory researchers have shown that the toughness of zirconia ceramics can be increased by controlling the grain size in ceria- and yttria-doped tetragonal zirconias and/or by co-doping with ceria and hafnia.

When stresses such as those which act at the tip of a crack are applied to a stabilized tetragonal zirconia matrix, much of the strain energy is used in causing the martensitic transformation of the material surrounding the crack, rather than propagating the crack. Therefore, the fracture resistance of the zirconia matrix is effectively increased.

Toughness of the stabilized zirconia is influenced by the amount, type, and combination of solute(s) used to stabilize the $\mathrm{t}-\mathrm{ZrO}_{2}$ phase and by the starting microstructure and grain size. Research at the Oak Ridge National Laboratory has demonstrated how these factors effect critical transformation characteristics such as the martensite-start $\left(M_{S}\right)$ temperature, transformation zone size, and transformation stress.

PATENT STATUS: $\quad$ U.S. Patent 4,971,933. 


\title{
Joining Ceramics
}

\author{
A. J. Moorhead \\ (615) 574-5153 \\ Metals and Ceramics Division \\ Oak Ridge Nationai Laboratory \\ Oak Ridge, Tennessee 37831
}

The successful attainment of many of the proposed advanced applications for structural ceramics (such as in heat engines or heat exchangers) is dependent on the technology for reliably joining ceramic components to form complex assemblies, unit lengths of ceramic material to form large systems, or ceramic components to metals. A series of new filler metals for direct brazing of structural ceramics to themselves and to metals has been developed at the Oak Ridge National Laboratory.

Two types of brazing processes are used to join ceramics. In indirect brazing, the ceramic is coated with a metal such as molybdenum or titanium prior to brazing with a nonreactive commercial filler metal. The metalizing used in this process is complicated and expensive, and the strength of the coating-ceramic bond and the corrosion resistance of the coating are of concern. Direct brazing, in which ceramics are joined using a filler metal specially formulated to wet and bond the ceramics, is preferred because it avoids these problems.

The new filler metals are in the composition range of $35-50 \mathrm{Cu}, 40-50 \mathrm{Ag}$, 1-15Ti, and 2-8Sn (all at. \%). Tin is present in these filler metals in sufficient quantities to lower the melting points without causing embrittlement. Accordingly, the alloys can be cold rolled into foil, with about $25 \%$ reduction in thickness between anneals. Although these filler metals wet and strongly adhere (when brazed at $800^{\circ} \mathrm{C}$ ) to many structural ceramics including alumina, transformationtoughened zirconia, and SiC-whisker reinforced alumina, they maintain high joint flexural strengths $>200 \mathrm{MPa}(29 \mathrm{ksi})$ to temperatures up to $600^{\circ} \mathrm{C}$. The joints have also 'jeen shown to experience little degradation when exposed at $400^{\circ} \mathrm{C}$ to oxidizing atmospheres for times of at least $100 \mathrm{~h}$.

PATENT STATUS: $\quad$ U.S. Patent $4,735,866$. 
Fiber-Reinforced Ceramic-Matrix Composites

\author{
D. P. Stinton \\ (615) $574-4556$ \\ Metals and Ceramics Division \\ Oak Ridge National Laboratory \\ Oak Ridge, Tennessec 37831
}

As material requirements become more sophisticated, there is substantially greater emphasis on the development of advanced ceramics. One of the most successful techniques used to produce these new ceramics is chemical vapor deposition (CVD) in which a solid material is deposited from gaseous precursors onto a substrate that is typically heated to promote the deposition reaction.

A new process for fabricating advanced ceramics using CVD is under development at Oak Ridge National Laboratory. Scientists are applying a process called chemical vapor infiltration (CVI) to create fiber-reinforced ceramic composites. Current commercial CVI processes are isothermal and require reactant gases to diffuse into the freestanding fibrous preform. Densification is inherently very slow because of the necessity for diffusion to carry the reactants into the preform and the gaseous reaction products back to the preform surface. The result is a process routinely requiring three weeks to saveral months to complete.

The ORNL process simultaneously utilizes thermal and pressure gradients to reduce the infiltration time from weeks to less than $24 \mathrm{~h}$. Fibrous preforms ( $\mathrm{SiC}$ or carbon fibers) are retained within a graphite holder that contacts a watercooled metal gas distributor, cooling the gas inlet surface of the substrate. The opposite end of the fibrous preform is exposed to the hot zone of the funiace, creating a steep temperature gradient across the preform. The reactant gases are forced under pressure into the cooled side of the fibrous preform, but initially do not react because of the low temperature. The gases continue from the cooled portion of the preform into the hot portion, where the matrix $\left(\mathrm{SiC}, \mathrm{Si}_{3} \mathrm{~N}_{4}, \mathrm{~B}_{4} \mathrm{C}\right.$, $\mathrm{TiB}_{2}$, etc.) begins to deposit on the fibers. Deposition of matrix material within the hot region of the preform increases the density and therefore the thermal conductivity of the preform. Thus, the deposition zone moves progressively from the hotter regions toward the cooler regions. The progress continues until reduced permeability of the densified composite prevents sufficient flow of reactant gases into the preform.

The method is well-suited for fabricating thick-walled (at least $25 \mathrm{~mm}$ ) composites of relatively simple shapes. The ORNL process is a marked improvement over other current commercial methods. Preforms that previously 
required weeks to densify nuw require less than $24 \mathrm{~h}$ and specimens with densities up to $95 \%$ of theoretical and strengths in the range of $400-450 \mathrm{MPa}$ have been produced. Also, the flexibility of the process has been demonstrated by the fabrication of tubes with diameters up to $50 \mathrm{~mm}$ and wall thicknesses of about $10 \mathrm{~mm}$. Most importantly, the materials fail noncatastrophically, exhibiting typical composite behavior (fracture toughness of approximateiy $25 \mathrm{MPa} \cdot \mathrm{m}^{1 / 2}$ ).

PATENT STATUS: $\quad$ U.S. Patent $4,580,524$. 


\title{
Fiber-Reinforced Composite Hot-Gas Filters
}

\author{
D. P. Stinton \\ (615) 574-4556 \\ Metals and Ceramics Division \\ Oak Ridge National Laboratory \\ Oak Ridge, Tennessee 37831
}

Particulate filters that operate at temperatures up to $1000^{\circ} \mathrm{C}$ will be required for cost-effective operation of advanced coal conversion systems. In these systems, contaminants such as sulfur, alkali metals, $\mathrm{NO}_{x}$ and solid particulates mus: be removed from the gas stream to protect metallic turbine or engine componen ts from corrosion and erosion. Commercially proven particulate removal techniques are available; however, the temperatures of the particulateladen gases exceed the maxinum service temperature of the available filters.

A number of techniques are being investigated for the removal of particulates from hot-gas streams, including fabric filters, crossflow filters, and candle filters. Unfortunately, each o these types of filters has serious limitations which prevents its use in coal conversion systems. Candle filters and crossflow filters are susceptible to brittle fracture. Thermal stresses due to reverse pulsing with cool cleaning gas often exceed the mechanical strength of the material. Fabric filters are very resistant to thermal shock but their strength is easily degraded by rough handling, excessive temperatures, or corrosion.

A new approach to high-temperature particulate filtration utilizing fiberreinforced composite technology has been developed at ORNL which overcomes the brittle nature that has plagued conventional candle and crossflow filters. Fiber-reinforced particulate filters consist of a mat or felt of ceramic fibers overcoated with a ceramic matrix (normally $\mathrm{SiC}$ ) by a chemical vapor deposition process. The ceramic overcoat bonds fibers together at crossover points and rigidizes the material. Current fiber-reinforced particulate filters appear promising because of their excellent filtering efficiency, high strength, corrosion resistance, and damage tolerance (particularly thermal shock resistance).

Commercial size ( $50 \mathrm{~mm}$ OD and $1.5 \mathrm{~m}$ long) fiber-reinforced candle filters are currently being fabricated by a subcontractor for evaluation in various pilot plants and test facilities.

PATENT STATUS: Application has been made. 


\title{
Titanium Diboride
}

\author{
A. J. Moorhead \\ (615) 574-5153 \\ Metals and Ceramics Division \\ Oak. Ridge National Labcratory \\ Oak Ridge, Tennessee 37831
}

The properties of refractoriness (melting point $\sim 2900^{\circ} \mathrm{C}$ ) and high hardness make the intermetallic compound $\mathrm{TiB}_{2}$ a candidate material for diverse applications. The refractory nature of $\mathrm{TiB}_{2}$ normally requires temperatures near $2000^{\circ} \mathrm{C}$ for fabrication to high density by hot pressing. However, earlier research showed that grain growth which occurs at these temperatures can be detrimental to mechanical properties. Microcracks caused by anisotropic thermal expansion in this hexagonal material occur if the grain size exceeds approximately $20 \mathrm{~mm}$, with a resultant degradation in mechanical properties.

Hot pressing of $\mathrm{TiB}_{2} \mathrm{cc}$. ' mics with nitrel as a densification aid in an inert atmosphere at $1550^{\circ} \mathrm{C}$ was successfully demonstrated. Such a low temperature minimizes grain growth and the resulting microcracks which develop at higher sintering temperatures. Several processing variables were investigated: hot pressing atmosphere and temperature, nickel content of the initial powder mixture, $\mathrm{TiB}_{2}$ powder sources and characteristics, and carbon additions. Nitrogen was not a suitable pressing atmcsphere, but compacts pressed in argon had densities and microstructures similar to those pressed in vacuum. The grain size was typically less than $10 \mathrm{~mm}$ and the microstructure contained a small amount of a nickel-rich phas at ine grain boundaries. Carbon additions in the range 0.5 to 2 wt $\%$ decreased the amount of this grain-boundary phase. Fracture toughness values ranged from 2.8 to $8.5 \mathrm{MPa} \cdot \mathrm{m}^{1 / 2}$ and the fracture stress ranged from 393 to $756 \mathrm{MPa}$, depending on procassing variables.

The laboratory-ieveloped process has been used by a commerciai fabricator to hot press (in argon) tiles having nominal dimensions of $15 \times 15 \times$ $2.5 \mathrm{~cm}$ and $25 \times 25 \times 5 \mathrm{~cm}$ for comparison with tiles pressed in vacuum by another fabricator.

PATENT STATUS: $\quad$ U.S. Patent $4,812,280$. 


\title{
Fabrication of High-Field Zinc Oxide Varistors by Sol-Gel Processing
}

\author{
R. J. Lauf \\ (615) 574-5176 \\ Metals and Ceramics Division \\ Oak Ridge National Laboratory \\ Oak Ridge, Tennessee 37831
}

A varistor is an electrical resistor that does not obey Ohm's law; that is, the current $I$ flowing through the varistor is not proportional to the applied potential $V$. In general, the electrical behavior of the varistor is described empirically by the relation $I=\mathrm{CV} \alpha$, with $\mathrm{C}$ a constant; the nonlinear exponent, $\alpha$, ranges from about 5 to 25 for varistors based on $\mathrm{ZnO}$.

For a given device, $\alpha$ is not constant, but passes through a maximum as current density increases. The unique electrical properties of varistors make them suitable for use as surge arrestors or voltage limiters in electrical devices. In operation, the varistor is connected between the power line and electrical ground. When the line voltage exceeds the breakdown voltage $V_{b}$ (from either a lightning strike or switching operations), the surge is carried away through the varistor, thus protecting the circuit.

Advanced ceramic processing techniques were used to fabricate $\mathrm{ZnO}$ varistors having grain sizes in the $3-4 \mu \mathrm{m}$ range in commercial devices. The fine-grained varistors exhibited high breakdown fields compared to commercial materials. Processing steps included synthesis of highly active powders by sol-gel techniques and hot pressing at temperatures below about $800^{\circ} \mathrm{C}$ in a reducing environment to achieve high density. Heat treatment in ar at temperatures up to $1000^{\circ} \mathrm{C}$ fully developed the nonohmic electrical properties.

Recent work has demonstrated that sol-gel varistors can also be fabricated by cold pressing and sintering.

PATENT STATUS: $\quad$ U.S. Patent $4,510,112$. 


\title{
Zirconia-Bonded Zirconia Fïber Insulation Structures
}

\author{
G. E. Wrenn \\ (615) $574-3860$ \\ Program Management Division \\ Y-12 Plant \\ Oak Ridge, Tennessee 37831
}

\begin{abstract}
Zirconia-bonded zirconia fiber insulation structures are a class of lightweight, monolithic insulators that have been developed for use at temperatures greater than $2000^{\circ} \mathrm{C}\left(3600^{\circ} \mathrm{F}\right)$ in all types of furnace atmospheres. The insulation structures contain $80-85$ vol \% porosity and have bulk densities below $1.0 \mathrm{~g} / \mathrm{cm}^{3}(60 \mathrm{pcf})$. These insulators are self-supporting and have low thermal mass for fast cycle times in furnace operations.
\end{abstract}

Such structures are produced using filtration molding techniques. Disks, cylinders, frustra, and a variety of other geometric shapes are produced with wall thicknesses of up to $2.5 \mathrm{~cm}(1.0 \mathrm{in}$.). Fibers in the structures are deposited in orientations that produce maximum resistance to conductive heat flow through the walls of the structures.

Process furnaces equipped with these zirconia fiber insulating structures can be operated at sustained temperatures to $2300^{\circ} \mathrm{C}\left(4200^{\circ} \mathrm{F}\right)$, compared to the $1700^{\circ} \mathrm{C}\left(3100^{\circ} \mathrm{F}\right)$ upper limit of existing oxide fiber-lined furnaces. This will enable industrial processing of new alloys and ceramic materials that contain higher concentrations of refractory elements. The zirconia structures can also serve as hot-gas filters and substrates for production of high-density ceramic composites.

PATENT STATUS: $\quad$ U.S. Patents 4,743,340; 4,770,930. 


\title{
Pulsed Eddy-Current Nondestructive Testing
}

\author{
C. V. Dodd \\ (615) $574-4839$ \\ Metals and Ceramics Division \\ Oak Ridge National Laboratory \\ Oak Ridge, Tennessee 37831
}

Pulsed eddy curients contain a wide band of frequency components that can be used to identify many different material properties. New pulsed eddycurrent equipment developed at the Oak Ridge National Laboratory has made possible accurate nondestructive evaluations of materials under conditions that previously made such tests impossible.

The new system has been tested in the nondestructive evaluation of ferromagnetic steam generator tubing from the boreside, and was able to detect small flaws near the outside of this tubing in the presence of other artifacts on the outer surface. This kind of test was not possible with nonpulsed eddy-current nondestructive testing (NDT) equipment because eddy currents cannot penetrate deeply into ferromagnetic material unless their operating frequency is very low, and small flaws are difficult to detect at low frequencies.

In the new system, a large current pulse applied to a driver coil produces magnetic saturation throughout the wall of the tube. When the material is magnetically saturated, eddy currents can penetrate even at the high frequencies needed to detect small flawc The field produced by the driver coil induces a pulse in a pickup coil. The pulse shape is dependent on the electromagnetic properties of the tube as well as the driving pulse. At selected times, the heights of the output pulses are computer-correlated with calibration data taken from machined standard tubing.

The magnitude and length of the pulse can be increased to saturate thicker tubes or shortened for very thin sections of ferromagnetic materials. Tube walls $5 \mathrm{~mm}$ thick have been tested with pulses of $500 \mathrm{~kW}$ peak power, and tubes $0.2 \mathrm{~mm}$ thick have been tested with $400 \mathrm{~W}$ pulses.

Other potential applications include the examination of very small or very poor conductors, both of which require the use of frequencies higher than those at which commercial multifrequency instruments can make accurate measurements. Graphite and some ceramics can be effectively evaluated using pulses, since some frequency components of the pulses are useful for measuring the desired properties. 
One very great advantage of the new system is that most of the changes required for different types of inspection can be made with simple software changes, instead of the more difficult and expensive hardware changes that would be needed with conventional multiple-fixed-frequency systems.

At present, there are no commercial manufacturers of this equipment.

PATENT STATUS: $\quad$ No application has been made. 
The Sigmajig: An Improved Hot-Cracking Test

\author{
G. M. Goodwin \\ (615) $574-4809$ \\ Metals and Ceramics Division \\ Oak Ridge National Laboratory \\ Oak Ridge, Tennessee 37831
}

Hot cracking (fissuring) is a significant problem which can affect the weldability of a large number of metallic materials. Stainless steels, superalloys, aluminum, copper-based alloys, and numerous more exotic formulations are all prone to hot cracking if the conditions exist.

The Varestraint and Tigamajig tests currently used to evalucte hot-cracking sensitivity cannot be used on thin sheets $(<3 \mathrm{~mm}$ thick). Existing thin sheet hotcracking tests rely on self-imposed restraint and are at best semiquantitative. The Sigmajig test system makes it possible to quantitatively test the tendency of even thin sheets of material to fissure.

The Sigmajig equipment applies a transverse stress (sigma, hence the name) to a $50 \times 50 \mathrm{~mm}$ square sheet specimen, followed by autogenous gas tungsten arc welding. As the preapplied stress is increased, cracking occurs. In all cases, cracking will eventually occur, even if the specimen is extremely hotcrack resistant.

The Sigmajig has been tested on 0.25-mm-thick specimens of types 304 and 316 stainless steel. Ranking of the heats agrees completely with prior results from other thin sheet tests (the Lambert and Oak Ridge National Laboratory Circular Patch tests), and the Sigmajig tests provide quantitative indices unavailable from the other tests.

The Sigmajig shows potential for use in several areas of application. Its ability to rank heats of an alloy suggests that it can be used to help control quality, and its sensitivity to welding parameters should help to develop detailed welding procedures to avoid cracking and maximize production.

It is expected that the Sigmajig will work on other thicknesses, alloys, and processes than those tested so far.

PATENT STATUS: $\quad$ U.S. Patent 4,763,521. 


\title{
Laser Diffraction Methods for High-Temperature Strain Measurements
}

\author{
K. C. Liu \\ (615) 574-5116 \\ Metals and Ceramics Division \\ Oak Ridge National Laboratory \\ Oak Ridge, Tennessee 37831
}

Since advanced ceramics were introduced as possible high-temperature structural materials, it has become important to learn the mechanical properties of these materials at high temperatures. However, strain measurement is extremely difficult to conduct in hostile environments using conventional methods.

Although conventional resistance strain gages are excellent at ambient temperatures, offering precise measurements in the magnitude of a few microstrain ( 1 microstrain is defined as $10^{-6} \mathrm{~m} / \mathrm{m}$ ), there are presently no resistance strain gages for use at temperatures above $1000^{\circ} \mathrm{C}$. A mechanical strain extensometer developed at the Oak Ridge National Laboratory can be used at high temperature.

A simple, low-cost, laser-based diffractive strain extensometer has been developed at the Oak Ridge National Laboratory. This device can be used for a variety of mechanical properties testing on metallic specimens as well as ceramic specimens. It offers excellent accuracy, long-term stability in hostile environments, and the advantages of noncontacting features that mechanical extensometers lack.

When a beam of well-collimated light produced by a low-power HeNe laser passes through a narrow slit (formed by two ceramic fiducial flags attached to the ceramic specimen), the light waves diffracted by the edges of the ceramic flags form an array of interference fringes. A photodetector camera is used to count the number of the fringes moving past the detector aperture, when the slit opening changes. Because the change in the gap width is a direct manifestation of the change in the gage length, the average strain can be calculated as a function of the fringe number intercepted at the photodetector. This system is used to measure dynamic or static strain.

The same equipment can also be used to measure strain under static or extremely slow strain-rate testing such as creep. In this case, snap shots of the interference fringe pattern are taken periodically and the images are digitized and saved in computer diskettes for data analyses. The average stiain is calculated as a function of the fringe spacing. 
The optical strain extensometer has been calibrated with an aluminum tensile specimen instrumented with resistance strain gages. Results show that the accuracy of the optical extensonter is comparable to that of the foil strain gages.

PATENT STATUS: $\quad$ No application has been made. 


\title{
MHD Molten Metal Atomizer for Powder Production and Thermal Spraying
}

\author{
V. K. Sikka \\ (615) $574-5112$
}

Metals and Ceramics Division

Oak Ridge National Laboratory

Oak Ridge, Tennessee 37831

Magnetohydrodynamic (MHD) forces can be applied to a stream of molten metal by passing the stream between two current-carrying electrodes which are, in turn, mounted between the pole faces of a strong electromagnet. The metal completes the circuit between the electrodes and a force is exerted on the metal stream at right angles to the plane containing the current and magnetic flux directions. This force accelerates the metal flow sufficiently to cause atomization. (Accelerations of more than $60 \mathrm{~g}$ have been calculated.)

Atomization is accomplished without the use of either pressurized water or pressurized gas streams. The elimination of the need for a pressurized atomizing medium should make it possible to operate the system in vacuum or a lowpressure inert gas atmosphere, which in turn would make it possible to operate at higher temperatures than can presently be used. Higher temperatures are needed to atomize refractory metals and alloys such as steels and superalloys.

The MHD molten metal atomizer can be used to either produce metal powders or to spray a thin metal coating on a substrate. The size distribution of metal powders produced using MHD are comparable to the size distributions of powders produced using commercial pressurized-argon atomization.

Research is currently under way on methods to increase powder production to commercial volumes, to further refine powder sizes, and to produce thick coatings on substrates.

PATENT STATUS: U.S. Patent 4,919,335. 


\title{
Microwave Sintering of Ceramics
}

\author{
Ronald L. Beatty \\ (615) 574-4536 \\ Metals and Ceramics Division \\ Oak Ridge National Laboratory \\ Oak Ridge, Tennessee 37831
}

Recognizing the potential impact of microwave processing on the field of advanced ceramics, ORNL initiated a microwave materials processing project in 1985. Using rnicrowave technology developed by ORNL for the U.S. Department of Energy (DOE) Fusion Energy Program, unique microwave furnaces have been developed for uniformly heating ceramic parts of large size to temperatures in excess of $2000^{\circ} \mathrm{C}$. Advantages of the microwave furnaces over conventional furnaces include not only the ability to work with large and complex-shaped ceraniic components, but also to uniformly heat materials at fast processing rates (up to $200^{\circ} \mathrm{C} / \mathrm{min}$ ). Because the microwave furnace has no heating element, processing can be accomplished in vacuum and in inert, oxidizing, or reducing atmospheres. Also, because the hot zone of the furnace is confined to the region immediately around the workpiece, impurities that might otherwise migrate into the part being fired are greatly reduced.

ORNL scientists have demonstrated that many ceramic materials can be processed faster and at lower temperatures using microwaves than is possible conventionally. In their initial studies, they showed that aluminum oxide, which is conventionally processed at $1400^{\circ} \mathrm{C}$, can be microwave processed at $1000^{\circ} \mathrm{C}$. They also showed that the properties of the microwave-fired aluminum oxide are better than those achieved by conventional firing. In fact, the strength of the microwave-fired samples compares favorably with that of samples produced by not pressing, an expensive and time-consuming technique that combines high temperatures and high pressures to effect densification of the ceramic. Other materials that have been improved by microwave firing include zirconium oxide, titanium diboride, silicon nitride, and glass.

Microwave processing holds tremendous potential for fabricating improved materials. Because microwaves heat ceramics uniformly and quickly, processing times can be reduced and the strength can be improved for large ceramic parts such as lightweight armor for helicopters and tanks. Electrical ceramics may benefit from the improved chemical and microstructural control afforded by microwave processing. Even more exciting than improving the properties of existing materials is the prospect that microwave processing may permit the development of new materials and material systems. For example, one promising application is in the development of cernmic composites. Ceramics can be 
microwave-fired at temperatures as much as $400^{\circ} \mathrm{C}$ lower than in a conventional furnace. Therefore, many metals can be co-fired with a ceramic in a microwave furnace that could not be used conventionally because they would melt. An example would be the development of a multilayer integrated circuit substrate that uses copper wires instead of the currently used molybdenum or tungsten wires.

Because of the potential of the microwave processing technology, we have both applied and theoretical research projects in place. The applied effort is aimed at improving the properties of advanced structural ceramics such as silicon nitride, silicon carbide, zirconia, and zirconia-toughened alumina. The theoretical program is designed to help us understand why microwave processing is so beneficial to the processing of ceramics. In addition, we are establishing vehicles for industry to participate with us in these programs.

PATENT STATUS : Applications have been made. 


\title{
The Thermomechanical Model Software Development Center: A Technology Transfer Initiative
}

\author{
P. T. Carlson and R. R. Judkins \\ (615) $574-4572$ \\ Metals and Ceramics Division \\ Oak Ridge National Laboratory \\ Oak Ridge, Tennessee 37831
}

The Thermomechanical Model Software Development Center (TMSDC) consortium has been formed to develop a user-friendly and intelligent computer software for the analysis of thermomechanical stresses in refractory systems. The purpose of the consortium is to transfer to the industrial sector information gained on the Fossil Energy Advanced Research and Technology Development (AR\&TD) Materials Program on the thermomechanical analysis of refractory linings for coal gasification systems in a form that will be most useful to refractory manufacturers and users. The software will have broad application to a wide variety of industrial processes using high-temperature refractories under high-stress conditions.

The software is based on a comprehensive computer model for various refractory materials, in which mathematical representations of temperature-dependent thermophysical properties such as thermal conductivity, density, specific heat, and coefficient of thermal expansion lead to the development of temperature-, time-, and load-history-dependent models of candidate refractory materials. The models have been incorporated into a finite-element program for the prediction of the thermomechanical behavior of refractories. The software can be conveniently and efficiently used in routine engineering situations, requiring decisions on choices and applications of refractories. Version 0.8 of the software was releaseci in February 1990. This version includes the interactive user interface, the commor database routines, the materials property library, and portions of the finite-element solver and the post-processing utility routines. Version 1.0, released in August 1990, includes a fully functional finite-element solver, post-processing utilities, and a complete set of documentation.

The TMSDC is managed by the Tennessee Center for Research and Development (TCRD) and is jointly funded by 12 industrial firms and the Department of Energy, through Martin Marietta Energy Systems, Inc. The development of the software is being perfurmed by Integrated Engineering Design, under contract with TCRD. The Advisory Board of the TMSDC has the responsibility of reviewing progress of the software development and making 
recommendations. The Board is comprised of representatives from the 12 member companies, the Fossil Energy ARi TD Materials Program, and the DOE Oak Ridge Operations Office.

PATENT STATUS: $\quad$ No application has been made. 


\title{
Process for Impregnating a Concrete or Cement Body with a Polymeric Material
}

\author{
A. J. Mattus \\ (615) 576-1795 \\ Chemical Technology Division \\ Oak Ridge National Laboratory \\ Oak Ridge, Tennessee 37831
}

The need to completely impregnate solid materials with various types of polymers for the purpose of imparting desirable properties such as impermeability to water, protection from environmental chemical attack, or simply to produce a stronger material has been the goal of researchers for many years. The desire to impregnate such materials has been limited substantially by the presence of contained water, especially in the case of concrete or waste-containing grout, and success has only been realized following complete drying and high-pressure entry methods. However, these methods have been shown to be highly uneconomical for full-scale practical use; and as a result, only specialized, limited use is made of polymers in, for example, the construction concrete and waste-processing industries.

A simple way to effect polymer entry into materials such as dense, cement-based grout containing liquid waste has been developed with potential application using other materials and various polymers. The method, which has rendered alkaline, cement-based grout impervious to attack by even concentrated acid, is still being evaluated. It is based on the use of pore-entry particles that permit entry by opening a network of channels inside very dense materials such as grout, despite the presence of water. The method will require no special equipment and appears to be easily adaptable to practical industrial scale-up.

PATEN T STATUS: $\quad$ U.S. Patent $4,828,761$. 


\section{For Further Information. . .}

For mor's information on any of the technologies described in Oak Ridge National Laboratory Materials Highlights, contact:

James R. Weir, Jr.

Oak Ridge National Laboratory

Building 4500-S, Mail Stop 6134

P.O. Box 2008

Oak Ridge, Tennessee 37831-6134

(615) $574-4064$

cr return this page to the above address and a catalog of the articles available on these technologies will be sent to you.

NAME

TITLE

ORGANIZATION

ADDRESS

CITY

STATE

ZIP CODE

TELEPHONE NUMBER 

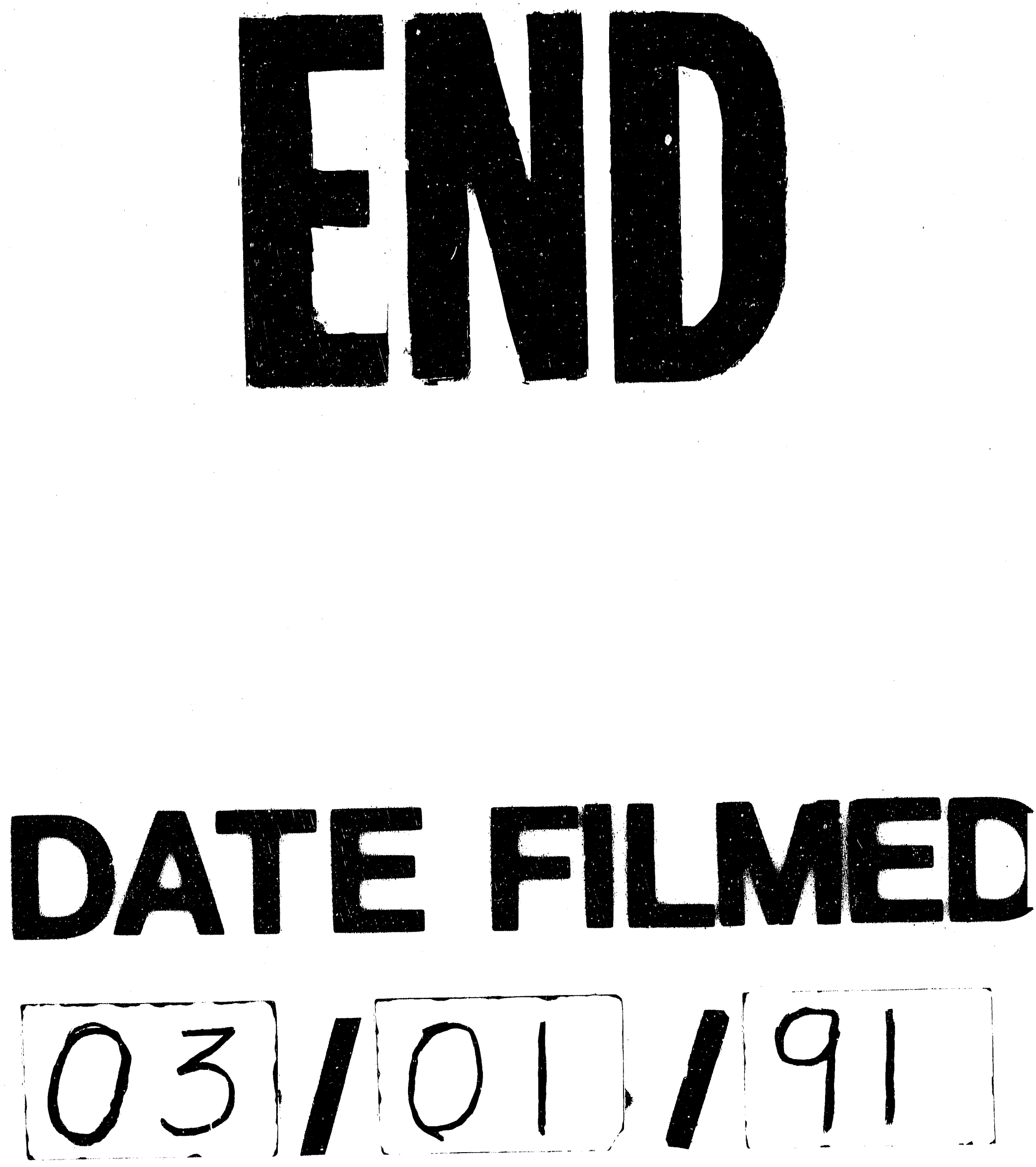
